\title{
Children's Hospital of Philadelphia Score to predict severe retinopathy in Indian preterm infants
}

\author{
Suraj Doshi ${ }^{1} \cdot$ Saumil Desai ${ }^{1} \cdot$ Ruchi Nanavati ${ }^{1}$ Nandkishor Kabra ${ }^{1} \cdot$ Snehal Martin $^{2}$
}

Received: 11 September 2018 / Revised: 24 February 2019 / Accepted: 15 March 2019 / Published online: 8 April 2019

(c) The Royal College of Ophthalmologists 2019

\begin{abstract}
Background Retinopathy of Prematurity (ROP) screenings are expensive and entail heavy workload. Predictive models using postnatal weight gain reduces the number of ophthalmological examinations. The objective was to validate Children's Hospital of Philadelphia (CHOP) score to predict severe ROP in resource limited settings.

Methods Prior to ophthalmic examination, the CHOP score was calculated to predict severe ROP (point estimate $=0.014$ ) in 191 preterm infants. Cut-off point estimate, most suitable in resource limited settings was assessed.

Results CHOP Score cutoff point (0.014) showed 67\% sensitivity, 75\% specificity. With CHOP score cut-off point $(0.010)$, the corresponding values were $100 \%$ sensitivity, $51 \%$ specificity, PPV $12 \%$ and NPV $100 \%$.

Conclusion CHOP Score (0.014) is a poor tool to predict the onset of severe ROP. However, CHOP Score $(0.010)$ is a promising tool to predict the onset of severe ROP and reduces the need for ophthalmological examinations by $50 \%$ in resource limited settings.
\end{abstract}

\section{Introduction}

Retinopathy of prematurity (ROP) is the most common disease leading to childhood blindness among preterm infants [1-3]. Out of 27 million annual live births in India, approximately 2 million are $<2000 \mathrm{~g}$ in weight and are at risk of developing ROP [4]. In India, the incidence of ROP is between $38-52 \%$ in low birth weight infants $[4,5]$.

Current ROP screening criteria is are a simple prediction model with 2 dichotomized (yes or no) predictors, birth weight (BW) and gestational age at birth (GA). In India, as per the National neonatology Forum Guidelines, ROP screening should be performed in all preterm infants born $<34$ weeks gestation and/or $<1750 \mathrm{~g}$ birth weight; as well as in infants $34-36$ weeks gestation or $1750-2000 \mathrm{~g}$ birth weight if they have risk factors for ROP [4]. Such screening models have high sensitivity, but they are not

Saumil Desai

drsaumildesai@gmail.com

1 Neonatology Department, Seth GS Medical College and King Edward Memorial Hospital, Mumbai, India

2 National Institute of Immunohaematology, Indian Council of Medical Research, Mumbai, India specific. In fact, less than $5 \%$ of infants examined require laser surgery, based on multiple large US [6], Canadian [7], and UK $[8,9]$ studies. Repeated ophthalmological examinations lead to stress, pain and physical impairment in these fragile preterm infants. All screening programs are time consuming, labor intensive and uncomfortable. They cause anxiety to parents and sometimes lead to an extended NICU stay. Repeated ophthalmological examinations for ROP screening are expensive and remain a major constraint for resource limited settings like India. Hence there is a need to develop better predictive models to address this issue.

Recent studies suggest that the use of prediction models that include postnatal weight gain may greatly reduce the number of infants requiring examinations while still accurately identifying infants who will require treatment $[10$ 12]. The scientific rationale is that low weight gain is a surrogate measure for a slower-than expected rise in serum insulin-like growth factor-1 (IGF-1), which results in insufficient activation of retinal vascular endothelial growth factor by IGF-1 and poor retinal vascular growth early in postnatal life [13-16]. With a similar rationale, a scoring system Childrens Hospital of Philadelphia (CHOP Score) was developed by Binenbaum \& colleagues to predict the occurrence of ROP severe enough to require treatment among preterm infants [17]. 
Among 524 infants, the model had $100 \%$ sensitivity for type 1 ROP, while reducing the number of infants requiring examinations by $49 \%$. This scoring system will allow for a reduction in the number of eye examinations performed in the same infant during ROP screening. Those at low risk, any stage ROP, will also be spared from repeated examinations reducing the pain and stress on the infant and, furthermore, reducing the workload. This will help to focus on those infants who require attention in terms of treatment. The investigators have stressed the need to further validate this predictive model in other populations [17].

A clinically reliable and cost-effective model to predict a serious health condition like ROP is very important for a resource limited low middle-income country like India. Hence the objective of our study is to describe the use of CHOP score as a model to predict the onset of severe ROP and its comparison with the ophthalmological examination i.e., Indirect Ophthalmoscopy for detecting ROP (gold standard) in an Indian setting.

\section{Patients and methods}

Ethical approval for the study was obtained from the Institutional ethics committee. This was a prospective observational study carried out in a level III NICU of a tertiary level hospital in western India for a period of 6 months (March to August 2017).

Sample size calculation was made using formula for sensitivity \& specificity studies. Based on PINT- ROP model study we assumed sensitivity \& specificity of $95 \%$. Prevalence of type 1 ROP in our unit is in study population of interest is $10 \%$. For a precision of $10 \%$, for the above sensitivity, specificity and prevalence, estimated sample size was 191 preterm infants.

Infants of gestational age $<34$ weeks and birth weight $<1750 \mathrm{~g}$, as per standard unit policy, (National Neonatology Forum Guidelines) were included for the study [4]. Those infants with major lethal congenital anomalies not compatible to life were excluded.

The primary outcome of the present study was to accurately predict the risk of type 1 ROP using the CHOP-ROP screening model. The secondary outcome was to demonstrate reduction in the need for ophthalmological examinations.

\section{Methods}

An informed consent regarding the study protocol was obtained from parents of the eligible preterm infants before enrolling them. The gestational age of the infant was assessed in the labor room by using date of last menstrual period and the first trimester ultrasonography. In case of non-availability of gestational age by date and by ultrasonography, the preterm infant was not enrolled for the study, though all the preterm infants were admitted in NICU as per unit policy.

The preterm infants were subjected to Indirect ophthalmoscopy for ROP screening at 4 weeks of age as per standard unit policy, recommended by the National Neonatology Forum Guidelines [4].

In case of any high-risk factors, like those infants who received oxygen therapy, assisted ventilation, multiple blood transfusions, PDA, IVH, were screened for ROP at 3 weeks post-natal age as per the existing unit policy.

Indirect ophthalmoscopy was done by pediatric ophthalmologist as a routine practice. Indirect ophthalmoscopy was considered as Gold standard for diagnosis of ROP. Staging of disease was recorded as per the 1984/1987 International Classification of ROP (Annexure 1). Type 1 and type 2 ROP was defined as per the Early Treatment for ROP (ETROP) guidelines (Annexure 2) [18]. The preterm infants were considered for treatment as per ETROP guidelines, being followed as standard of care.

Prior to the ophthalmological examination, a senior resident calculated the CHOP score (Fig. 1). The CHOP score (Fig. 1) was devised by Children's hospital of Philadelphia and consists of five parallel lines. Gestational age in weeks is plotted on the first line, daily weight gain $(\mathrm{gm} /$ day) on third line and birth weight in gms on the fifth line. The second line is the probability line which gives us the cut off/alarm level of 0.014 (plotted from 0.0001 to 0.9 ) above

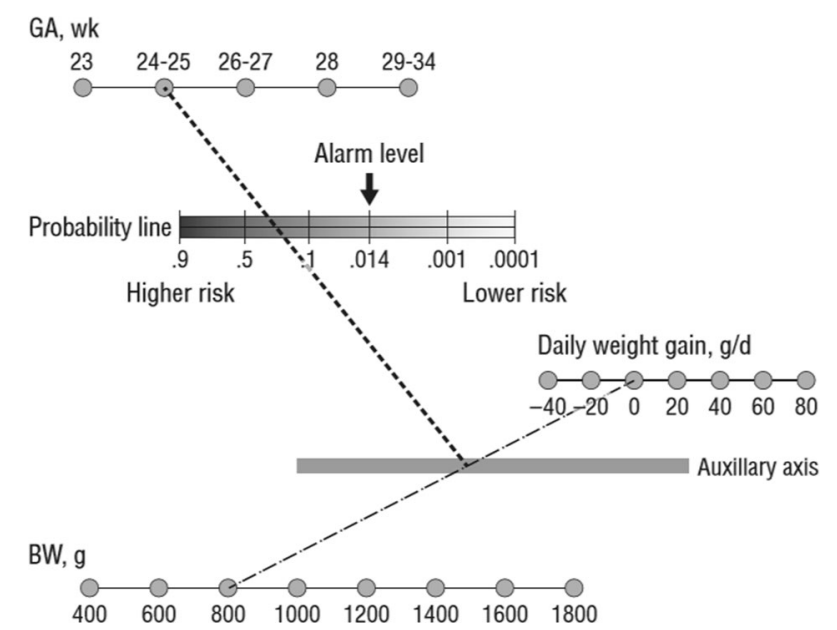

Fig. 1 Sample nomogram to predict the risk of severe ROP based on the CHOP ROP model. A straight line is drawn between the values for birth weight and daily rate of weight gain. The intersection of this line with the gray auxiliary axis is then connected to the value for GA. The intersection of this second line with the probability line provides the predicted probability of severe ROP. If the risk is greater than 0.014 , eye examinations are indicated. (From Binenbaum G, Ying GS, Quinn GE, et al. The CHOP postnatal weight gain, birth weight, and gestational age retinopathy of prematurity risk model. Arch Ophthalmol 2012;130(12):1560-5; with permission.) 
which the need for ophthalmological examination is established. The fourth line is the auxiliary axis. Now the line joining the birth weight (on fifth line) of a particular infant to the daily weight gain (on third line) of the same infant, intersects the auxiliary axis at one point. Another line joining the intersection point on auxiliary axis and the first line (on which gestational age is plotted) is then joined. This line will then intersect at a point on the probability line and if this intersection point is above the alarm level (0.014), this establishes the need for ophthalmological examination. The cut-off (0.014) has been established by the Children's hospital of Philadelphia based on their population, we validated the same for the present study. We assessed which cut-off point estimate would be most suitable for detecting all type 1 ROP in the study population.

The infants' weight was recorded daily on an electronic infant weighing scale with an accuracy of \pm 1 gram. Daily weight gain rate was calculated using daily measurements (the difference between the average of all available daily weights during the prior 7 days and the average of the previous week's daily weights, divided by 7 ). The difference in the weights were calculated from the third week of the post-natal age onwards as that is the earliest age from which severe ROP had been observed in the institute.

The senior resident and the ophthalmologist were blinded from each other's observations. Their observations were recorded on a pre-designed proforma.

\section{Statistical analysis}

All statistical analyses were performed using the Statistical Package for the Social Sciences (SPSS), version 15.0. for Windows (SPSS Inc., Chicago, IL, USA). Sensitivity, Specificity, Positive predictive values (PPV) and Negative predictive values (NPV) were used to assess the accuracy of the CHOP score to predict severe ROP.

\section{Results}

The study included data on 191preterm infants. Mean BW and GA for the entire cohort were $1341 \pm 212 \mathrm{~g}$ and $31.2 \pm$ 2.3 weeks. The demographic characteristics of the cohort are shown in Table 1 . The prevalence of any stage ROP in our sample was $61 / 191$ patients $(31.9 \%)$. The incidence of ROP severe enough to require treatment in this study was (12/191 patients) $(6.2 \%)$.

A CHOP Score cutoff point of 0.014 showed $67 \%$ sensitivity, $75 \%$ specificity, a PPV of $15 \%$, and an NPV of $97 \%$ as shown in Table 2. When the CHOP score cut-off point was lowered to 0.010 , the corresponding values were $100 \%$ sensitivity, $51 \%$ specificity, a PPV of $12 \%$ and a NPV of $100 \%$ (Table 3).
Table 1 Demographic characteristics

\begin{tabular}{llll}
\hline & $\begin{array}{l}\text { Total cohort } \\
(n)\end{array}$ & $\begin{array}{l}\text { Any ROP } \\
(n)\end{array}$ & $\begin{array}{l}\text { Severe ROP } \\
\text { (type 1) }(n)\end{array}$ \\
\hline $\begin{array}{l}\text { Number } \\
\text { Birth weight in grams }\end{array}$ & $\begin{array}{l}\text { (Distribution) } \\
\text { 500-749 }\end{array}$ & $61(31.9 \%)$ & $12(6.2 \%)$ \\
750-999 & 27 & 19 & 8 \\
1000-1249 & 36 & 32 & 3 \\
1250-1499 & 45 & 7 & 1 \\
1500-1749 & 43 & 3 & 0 \\
Birth weight in grams & $1341 \pm 212$ & $1198 \pm 146$ & $878 \pm 186$ \\
(Total) (Mean \pm SD) & & & \\
GA in weeks (Distribution) & & \\
24-26 & 29 & 21 & 8 \\
26-28 & 35 & 32 & 3 \\
28-30 & 44 & 6 & 1 \\
30-32 & 45 & 2 & 0 \\
32-34 & 38 & 0 & 0 \\
Mean GA in weeks & $31.2 \pm 2.3$ & $30.1 \pm 2.1$ & $28.5 \pm 1.6$ \\
(Total) (Mean \pm SD) & & & $11.56 \pm 7.77$ \\
$\begin{array}{l}\text { Mean weight gain } \\
\text { (grams/day) }\end{array}$ & $18.21 \pm 10.84$ & $14.41 \pm 8.54$ & \\
\hline
\end{tabular}

Table 2 CHOP score model with cut-off point $>0.014$

\begin{tabular}{lll}
\hline Sensitivity & $66.67 \%$ & $34.89-90.08 \%$ \\
Specificity & $74.58 \%$ & $67.50-80.81 \%$ \\
Positive likelihood ratio & 2.62 & $1.63-4.21$ \\
Negative likelihood ratio & 0.45 & $0.20-1.0$ \\
Disease prevalence & $6.35 \%$ & $3.32-10.83 \%$ \\
Positive predictive value & $15.09 \%$ & $9.97-22.20 \%$ \\
Negative predictive value & $97.06 \%$ & $93.65-98.66 \%$ \\
\hline
\end{tabular}

Table 3 CHOP score model with cut-off point $>0.010$

\begin{tabular}{lll}
\hline Sensitivity & $100.00 \%$ & $73.54-100,00 \%$ \\
Specificity & $51.40 \%$ & $43.83-58.92 \%$ \\
Positive likelihood ratio & 2.06 & $1.77-2.39$ \\
Negative likelihood ratio & 0.00 & - \\
Disease prevalence & $6.28 \%$ & $3.29-10.72 \%$ \\
Positive predictive value & $12.12 \%$ & $10.61-13.82 \%$ \\
Negative predictive value & $100.00 \%$ & - \\
\hline
\end{tabular}

\section{Discussion}

ROP develops in 2 phases, initially a hypoxic preclinical phase and subsequently a proliferative clinical phase. These result from alterations in serum insulin-like growth factor-1 (IGF-1), and vascular endothelial growth factor (VEGF), a hypoxia induced angio-proliferative factor necessary for 
normal retinal vessel formation [19]. Serum IGF-1 decreases with preterm birth from loss of maternal sources and poor endogenous synthesis [20-22]. IGF-1 plays a permissive role in VEGF induced retinal vascular growth [12, 13]. Hence, low serum IGF-1 hinders retinal vascular development, with localized hypoxia and VEGF accumulation, as metabolic demands increase within the developing retina. With increasing post-natal age and size, endogenous synthesis of IGF-1 increases, permitting VEGF activity, and proliferative retinopathy develops $[12,19,23]$. It is already known that prolonged early IGF-1 deficits and slow postnatal weight gain are associated with a higher risk of severe ROP [10, 11, 24, 25]. Serum IGF-1 levels correlate with fetal and postnatal growth, so postnatal weight gain is a good surrogate measure for serum IGF-1 [20, 22, 26]. Weight measurements are simple, quick and routinely done, whereas IGF-1 assays are expensive with a prolonged laboratory processing time. Several risk factors have been reported as involved in the development of ROP, but BW and GA are considered the most significant $[27,28]$. Currently, low post-natal weight gain after preterm birth is widely accepted as a predictive parameter for later development of ROP, being considered better than BW and GA as predictors $[29,30]$.

Several scoring systems, from the classic Apgar score to modern illness severity scores such as CRIB, SNAP and SNAPPE-II, have been routinely used to predict various neonatal comorbidities. Previously, studies have attempted to demonstrate the efficacy of CRIB, SNAP, and SNAPPE scores to predict ROP. The authors reported that none of the scores had sufficient power to predict ROP-induced vision impairment [31, 32]. A possible explanation for the poor performance of these scores as predictors of ROP may lie in the fact that such scores are done on the preterm infant's first day at the NICU and does not necessarily reflect the clinical behavior in the ensuing weeks. In order to be effective in terms of ROP detection, a scoring system should incorporate variables that take into account the subsequent weeks of life with several physiological or pathological processes [33].

Recently, clinical prediction models to identify preterm infants with risk of severe ROP were presented. WINROP, ROP Score, PINT-ROP were presented using postnatal longitudinal weight gain measurements. WINROP demonstrated a very high sensitivity for detecting severe ROP in retrospective studies: $100 \%$ in a Swedish cohort of 353 infants, reducing the number of preterm infants who would have received examinations by almost $76 \% ; 100 \%$ in a Boston cohort of 318 infants, reducing infants who needed ophthalmological examinations by $75 \%[34,35]$. However, when WINROP model was studied in developing countries, the sensitivity decreased: $91 \%$ in a Brazilian cohort of 366 infants and a very low 55\% in a Mexican cohort of 352 infants $[36,37]$. Further, the WINROP algorithm involves complex calculations, which becomes a limiting factor.

ROP Score model consists of a logistic regression equation, used to calculate risk only once per infant [38]. This model includes birth weight, gestational age, weight gain at a single time point ( 6 weeks postnatal age) and dichotomous factors for blood transfusion and use of oxygen in mechanical ventilation during the first 6 post-natal weeks. ROP Score had a sensitivity of $98 \%$ and specificity of $56 \%$ for severe ROP in a cohort of 474 Brazilian infants [38].

A similar scoring system Premature Infants in Need of Transfusion (PINT-ROP) to predict the occurrence of severe ROP warranting treatment [39]. They prospectively collected data from 367 preterm infants with BW $<1000 \mathrm{~g}$ in the Premature Infants in Need of Transfusion (PINT) randomized controlled trial to develop a model containing terms for BW, GA and daily rate of weight gain (calculated from the current and prior week's weight measurements). The equation was calculated every week and if the predicted risk of ROP was greater than a cut off level, ophthalmological examinations were indicated. In this manner, PINT ROP had $100 \%$ sensitivity for treated severe ROP, while reducing the number of infants requiring examinations by almost one third in that high-risk cohort.

The PINT ROP cohort was at high risk for ROP. Therefore, Binenbaum and colleagues applied the same modeling approach to a low-risk cohort more representative of current US ROP screening criteria (BW $<1501 \mathrm{~g}$ ) to develop a model called CHOP ROP. Among 524 infants, the model had $100 \%$ sensitivity for type 1 ROP, while reducing the number of infants requiring examinations by almost half. If the risk cutoff was raised to miss 1 infant requiring laser, the reduction in examinations was as high as $79 \%$. In the present study, cutoff point of 0.014 for severe ROP was used as per CHOP ROP model. At these cutoff points, CHOP Score showed 67\% sensitivity and 75\% specificity for severe ROP in the present study. Positive predictive value (PPV) refers to the probability of a preterm infant with a score above 0.014 developing ROP, whereas Negative predictive value (NPV) corresponds to the probability of a preterm infant with a score below 0.014 not developing severe ROP. For the cutoff point of 0.014, PPV and NPV were 15 and $97 \%$ respectively. This reduced the number of ophthalmological examinations by almost $75 \%$. However, when the cut-off point was lowered to 0.010 , the values of sensitivity, specificity, positive predictive and negative predictive were $100,51,12$ and $100 \%$ respectively and reduced the number of ophthalmological examinations by $50 \%$

This score is very simple to be routinely used by ophthalmologists, the NICU staff and trained health care workers during screening examination for detection of 
severe ROP. According to the score, the ophthalmologist in charge will decide which babies should receive more or less frequent re-evaluations in the weeks following the initial examination. Higher scores lead to more evaluations because these infants have more risk of developing severe ROP than patients with lower scores. It is worth mentioning that the use of CHOP score did not influence the usual established criteria for inclusion of preterm infants in the ROP screening during the present study. This score can be helpful in order to reduce the excessive number of eye examinations performed in preterm infants that had low scores.

The present study has a few merits like its prospective nature and encompassing all gestational ages in a setup representing majority of resource limited developing countries, as it was conducted in a major tertiary level referral unit in western India.

There are a few limitations in the present study. Firstly, the $95 \%$ confidence intervals for the present study are not narrow enough for the neonatologists to feel confident about widespread application of this prediction model. More studies with larger sample size are required to address this issue. Secondly, the CHOP ROP model with cut-off point (0.014) similar to American study, performed poorly in predicting onset of severe ROP in the current study may be due to differences in ROP pathophysiology, particularly in older GA infants. The additional insults of higher percentage of fetal growth restriction and sepsis in the developing world might be contributory. The same has been emphasized in previous studies and hence the need to establish customized cut-off points for each indigenous population, especially in the developing world. When the model's alarm level (0.010) was lowered (accepting a decreased specificity) it ensured $100 \%$ sensitivity. This could work well in a multitiered screening approach together with telemedicine, once both modalities have been adequately validated. Thirdly, other confounding factors were not analyzed in the present study.

Rather than replacing the existing guidelines, this model may be used alongside it, changing examination frequency or timing based on predicted risk.

Summarizing, CHOP Score is a promising tool that aims to reduce the excessive number of eye examinations performed in preterm infants, without missing any cases of severe ROP. Further studies are warranted to validate the usefulness of this score in other resource limited developing countries.

\section{Conclusions}

This study describes the use of CHOP Score to predict the occurrence of severe ROP in preterm infants. CHOP Score model with a cut-off point of 0.014 is a poor tool to predict the onset of severe ROP in Indian preterm infants. However, CHOP Score model with a cut-off point of 0.010 is a promising tool to predict the onset of severe ROP in Indian preterm infants and reduces the need for ophthalmological examination by $50 \%$. Further studies are warranted in similar resource limited settings to validate the above findings.

\section{Summary}

\section{What was known before}

- Repeated ophthalmological examinations for ROP screening in preterm neonates are stressful and expensive, which can be reduced by using a simple tool (CHOP score).

- However, it has been validated only in resource rich settings.

\section{What this study adds}

- CHOP Score model with a cut-off point of 0.014 is a poor tool to predict the onset of severe ROP in Indian preterm infants.

- However, CHOP Score model with a cut-off point of 0.010 is a promising tool to predict the onset of severe ROP in Indian preterm infants and reduces the need for ophthalmological examinations by $50 \%$.

Author contributions SD conceptualized and designed the study and revised the manuscript. SD collected the data and drafted the initial manuscript. RN supervised the data collection and critically reviewed the manuscript for important intellectual content. NK and SM critically reviewed the manuscript and carried out the statistical analyses. All authors approved the final manuscript as submitted and agree to be accountable for all aspects of the work.

\section{Compliance with ethical standards}

Conflict of interest The authors declare that they have no conflict of interest.

Publisher's note: Springer Nature remains neutral with regard to jurisdictional claims in published maps and institutional affiliations.

\section{References}

1. Gilbert C. Retinopathy of prematurity: a global perspective of the epidemics, population of babies at risk and implications for control. Early Hum Dev. 2008;84:77-82.

2. Fortes Filho JB, Eckert GU, Procianoy L, Barros CK, Procianoy RS. Incidence and risk factors for retinopathy of prematurity in 
very low and in extremely low birth weight infants in a unit-based approach in southern Brazil. Eye. 2009;23:25-30.

3. Quinn GE. Retinopathy of prematurity in Brazil: an emerging problem. J Pediatr. 2007;83:191-3.

4. Pejawar R, Vinekar A, Bilagi A. National Neonatology Foundation's Evidence-based Clinical Practise Guidelines 2010, Retinopathy of Prematurity. New Delhi: NNF India; 2010. p. 253-62.

5. Jalali S, Anand R, Kumar H, Dogra MR, Azad R, Gopal L. Programme planning and screening strategy in retinopathy of prematurity. Indian J Ophthalmol. 2003;51:89-99.

6. Chiang MF, Arons RR, Flynn JT, Starren JB. Incidence of retinopathy of prematurity from 1996 to 2000: analysis of a comprehensive New York state patient database. Ophthalmology. 2004;111:1317-25.

7. Lee SK, Normand C, McMillan D, Ohlsson A, Vincer M, Lyons C. Evidence for changing guidelines for routine screening for retinopathy of prematurity. Arch Paediatr Adolesc Med. 2001;155:387-95.

8. Haines L, Fielder AR, Scrivener R, Wilkinson AR. Retinopathy of prematurity in the UK I: the organisation of services for screening and treatment. Eye. 2002;16:33-8.

9. Royal College of Paediatrics and Child Health RCoO, British Association of Perinatal Medicine. UK Retinopathy of Prematurity Guideline May 2008. [PDF]. UK Retinopathy of Prematurity Guideline; 2008. Available at: http://www.rcophth.ac.uk/ core/core_picker/download.asp?id $=180 \&$ filetitle $=\mathrm{UK}+$ Retinopa thy + of + Prematurity + Guideline + May +2008 . Accessed Sep 17, 2012.

10. Hellström A, Engström E, Hård AL, Albertsson-Wikland K, Carlsson B, Niklasson A, et al. Postnatal serum insulin-like growth factor I deficiency is associated with retinopathy of prematurity and other complications of premature birth. Pediatrics. 2003;112:1016-20.

11. Löfqvist C, Andersson E, Sigurdsson J, Engström E, Hård AL, Niklasson A, et al. Longitudinal postnatal weight and insulin-like growth factor I measurements in the prediction of retinopathy of prematurity. Arch Ophthalmol. 2006;124:1711-8.

12. Hellstrom A, Perruzzi C, Ju M, Engstrom E, Hard AL, Liu JL, et al. Low IGF-I suppresses VEGF-survival signaling in retinal endothelial cells: direct correlation with clinical retinopathy of prematurity. Proc Natl Acad Sci USA. 2001;98:5804-8.

13. Smith LE, Shen W, Perruzzi C, Soker S, Kinose F, Xu X et al. Regulation of vascular endothelial growth factor-dependent retinal neovascularization by insulin-like growth factor-1 receptor. Nat Med. 1999;5:1390-5.

14. Moons KG, Altman DG, Vergouwe Y, Royston P. Prognosis and prognostic research: application and impact of prognostic models in clinical practice. BMJ. 2009;338:b606.

15. Grisaru-Granovsky S, Reichman B, Lerner-Geva L, Boyko V, Hammerman C, Samueloff A, et al. Mortality and morbidity in preterm small-for-gestational-age infants: a population-based study. Am J Obstet Gynecol. 2012;206:150e151-150e157.

16. Qiu X, Lodha A, Shah PS, Sankaran K, Seshia MM, Yee W, et al. Canadian Neonatal Network. Neonatal outcomes of small for gestational age preterm infants in Canada. Am J Perinatol. 2012;29:87-94.

17. Binenbaum G, Ying GS, Quinn GE, Huang J, Dreiseitl S, Antigua $\mathrm{J}$, et al. The CHOP postnatal weight gain, birth weight, and gestational age retinopathy of prematurity risk model. Arch Ophthalmol. 2012;130:1560-5. https://doi.org/10.1001/archophtha 1mol.2012.2524

18. Early Treatment for Retinopathy of Prematurity Cooperative Group. Revised indications for the treatment of retinopathy of prematurity: results of the early treatment for retinopathy of prematurity randomized trial. Arch Ophthalmol. 2003;121: 1684-94.
19. Pierce EA, Foley ED, Smith LE. Regulation of vascular endothelial growth factor by oxygen in a model of retinopathy of prematurity. Arch Ophthalmol. 1996;114:1219-28.

20. Langford K, Nicolaides K, Miell JP. Maternal and fetal insulin-like growth factors and their binding proteins in the second and third trimesters of human pregnancy. Hum Reprod. 1998;13:1389-93.

21. Lassarre C, Hardouin S, Daffos F, Forestier F, Frankenne F, Binoux M. Serum insulin-like growth factors and insulin-like growth factor binding proteins in the human fetus. Relationships with growth in normal subjects and in subjects with intrauterine growth retardation. Pediatr Res. 1991;29:219-25.

22. Lineham JD, Smith RM, Dahlenburg GW, King RA, Haslam RR, Stuart MC, et al. Circulating insulin-like growth factor I levels in newborn premature and full-term infants followed longitudinally. Early Hum Dev. 1986;13:37-46.

23. Aiello LP, Pierce EA, Foley ED, Takagi H, Chen H, Riddle L, et al. Suppression of retinal neovascularization in vivo by inhibition of vascular endothelial growth factor (VEGF) using soluble VEGF-receptor chimeric proteins. Proc Natl Acad Sci. 1995;92:10457-61.

24. Löfqvist C, Hansen-Pupp I, Andersson E, Holm K, Smith LE, Ley $\mathrm{D}$, et al. Validation of a new retinopathy of prematurity screening method monitoring longitudinal postnatal weight and insulin like growth factor I. Arch Ophthalmol. 2009;127:622-7.

25. Pérez Muñuzuri A, Fernández Lorenzo JR, Couce Pico ML, Blanco Teijeiro MJ, Fraga Bermúdez JM. Serum levels of IGF1 are a useful predictor of retinopathy of prematurity. Acta Paediatr. 2010;99:519-25.

26. Ahmad I, Zaldivar F, Iwanaga K, Koeppel R, Grochow D, Nemet $\mathrm{D}$, et al. Inflammatory and growth mediators in growing preterm infants. J Pediatr Endocrinol Metab. 2007;20:387-96.

27. Shah VA, Yeo CL, Ling YL, Ho LY. Incidence, risk factors of retinopathy of prematurity among very low birth weight infants in Singapore. Ann Acad Med Singapore. 2005;34:169-78.

28. Fortes Filho JB, Eckert GU, Valiatti FB, dos Santos PG, da Costa $\mathrm{MC}$, Procianoy RS. The influence of gestational age on the dynamic behavior of other risk factors associated with retinopathy of prematurity (ROP). Graefe's Archiv Clin Exp Ophthalmol. 2010;248:893-900.

29. Fortes Filho JB, Eckert GU, Tartarella MB, Procianoy RS. Prevention of retinopathy of prematurity. Arq Bras Oftalmol. 2011;74:217-21.

30. Wallace DK, Kylstra JA, Phillips SJ, Hall JG. Poor postnatal weight gain: a risk factor for severe retinopathy of prematurity. J AAPOS. 2000;4:343-7.

31. Eriksson M, Bodin L, Finnstrom O, Schollin J. Can severity of illness indices for neonatal intensive care predict outcome at 4 years of age? Acta Paediatr. 2002;91:1093-1100.

32. Hagadorn JI, Richardson DK, Schmid CH, Cole CH. Cumulative illness severity and progression from moderate to severe retinopathy of prematurity. J Perinatol. 2007;27:502-9.

33. Fortes Filho JB, Dill JC, Ishizaki A, Aguiar WW, Silveira RC, Procianoy RS. Score for neonatal acute physiology and perinatal extension II as a predictor of retinopathy of prematurity: study in 304 very-low-birth-weight preterm infants. Ophthalmologica. 2009;223:177-82.

34. Hellström A, Hård AL, Engström E, Niklasson A, Andersson E, Smith L, et al. Early weight gain predicts retinopathy in preterm infants: new, simple, efficient approach to screening. Pediatrics. 2009; 123:e638-45.

35. Wu C, VanderVeen DK, Hellström A, Löfqvist C, Smith LE. Longitudinal postnatal weight measurements for the prediction of retinopathy of prematurity. Arch Ophthalmol. 2010;128:443-7.

36. Hård AL, Löfqvist C, Fortes Filho JB, Procianoy RS, Smith L, Hellström A. Predicting proliferative retinopathy in a Brazilian 
population of preterm infants with the screening algorithm WINROP. Arch Ophthalmol. 2010;128:1432-6.

37. Zepeda-Romero LC, Hård AL, Gomez-Ruiz LM, GutierrezPadilla JA, Angulo-Castellanos E, Barrera-de-Leon JC, et al. Prediction of retinopathy of prematurity using the screening algorithm WINROP in a Mexican population of preterm infants. Arch Ophthalmol. 2012;130:720-3.
38. Eckert GU, Fortes Filho JB, Maia M, Procianoy RS. A predictive score for retinopathy of prematurity in very low birth weight preterm infants. Eye. 2012;26:400-6.

39. Binenbaum G, Ying GS, Quinn GE, Dreiseitl S, Karp K, Roberts $\mathrm{RS}$, et al. A clinical prediction model to stratify retinopathy of prematurity risk using postnatal weight gain. Pediatrics. 2011;127: e607-14. 